\title{
ANALISA PENAMBAHAN PENDAMPING KASIR UNTUK MENGURANGI ANTRIAN PADA RESTORAN PT.WENDYS TRANS BURGER
}

\author{
Wahyu Saputra **) dan Gempur Santoso *)
}

\begin{abstract}
Abstrak
PT. Wendys trans burger adalah suatu perusahaan Restoran makanan terkenal fast footnya. Restoran tersebut ramai pengunjung. Para kasir banyak yang mengeluh bingung dan kewalahan untuk mengatasi antriannya yang sampai melebihi kapasitas tempat dan tidak beraturan. Kami menggunakan metode Comparative Research Design agar dapat dilaksanakan untuk mencapai tujuan peneliti yaitu membandingkan waktu kebutuhan kecepatan antrian dengan menggunakan pendamping kasir dan tidak menggunakan pendamping kasir. Tempat yang diteliti adalah di PT. Wendys Trans Burger Jalan Dharma Husada no.124-126. Galaxy Mall Surabaya. Disana mengamati pembeli mengantri selama 10 hari. pengumpulan data peneliti menggunakan metode Observasi (pencatat) lama orang yang mengantri dengan menggunakan alat pensatat waktu (stopwocht). Hasil penelitian membandingkan rata rata (mean) antara menggunakan pendamping kasir dengan tidak menggunakan pendamping kasir dengan hasil selisihnya 4,755 menit. Untuk kesimpulan bahwa lama antrian bila menggunakan pendamping kasir lebih cepat di banding dengan tidak menggunakan pendamping kasir.
\end{abstract}

Kata kunci : Lama Antrian Penambahan, Pendamping kasir, Restoran

\section{PENDAHULUAN}

Antrian yang sangat panjang dan terlalu lama untuk memperoleh giliran pelayanan sangatlah menjengkelkan. Ratarata lamanya waktu menunggu (waiting time) sangat tergantung kepada rata-rata tingkat kecepatan pelayananya (Speed of services). banyak para pembeli (customer) mengeluh dikarenakan antriannya terlalu lama. Padahal setiap orang ketika ingin membeli sesuatu dari berangkat dan sampai ditempat dia ingin dapat langsung di layani. tetapi malah sebaliknya mereka harus mengantri terlebih dahulu. Antrian Menurut Siagian (1987), antrian adalah suatu garis tunggu dari nasabah yang memerlukan layanan dari satu atau lebih pelayanan (fasilitas). Pendamping kasir atau asisten kasir adalah orang yang membantu kasir untuk melengkapi pesanan yang telah di pesan oleh pembeli menurut A.Sobirin (1973). Pada banyak hal, tambahan fasilitas pelayanan dapat diberikan untuk mengurangi antrian atau untuk mencegah timbulnya antrian. Karena itu peneliti ingin mencari solusi memberikan pelayanan yang cepat,tapi disamping itu ia tidak ingin mengeluarkan ongkos yang terlalu besar untuk kepentingan itu. metode analisis penambahan pendamping kasir mungkin bisa memberikan solusi untuk mengurangi antrian yang menunggu lama pada perusahaan restoran PT.Wendys trans burger. Berdasarkan permasalahan yang ada diatas,maka perumusan masalah yang akan dibahas dalam penelitian ini adalah Apakah penggunaan pendamping kasir dapat mengurangi antrian yang terjadi pada PT.Wendys Trans Burger. Tujuan yang ingin dicapai dalam penelitian ini adalah Mengetahui lama antrian setelah menggunaan pendamping kasir.

\section{METODE PENELITIAN}

\begin{tabular}{llr}
\multicolumn{2}{c}{ Rancangan penelitian kami } \\
menggunakan metode Comparative \\
research & design. & (desaign
\end{tabular}

penelitian/rancangan penelitian). adalah suatu rencana tentang cara mengumpulkan mengolah data agar dapat dilaksanakan untuk mencapai tujuan penelitian. unsur rancangan penelitian adalah : jenis penelitian, populasi sasaran, metode sampling, besar sampling, cara pengumpulan data, cara pengolahan data, perlu tidak penggunaan statistik,cara pengambil kesimpulan. (Suparyanto, 2000). Populasinya pembeli makanan di Restourant wendys yang mengantri untuk memesan makanan dan Sampelnya mengamati pembeli dan mengantri selama 10 hari di Restourant wendys. Penelitian pengumpulan data menggunakan metode observasi (pencatatan). lama orang mengantri dengan menggunakan alat pencatat waktu (stopwocht) dan dicatat kedalam tabel.

\footnotetext{
**) Mahasiswa Teknik Industri

*) Dosen Teknik Industri

Universitas PGRI Adi Buana Surabaya
} 
Teknik analisa data Menggunakan Deskriptif komparatif yaitu membandingkan dua kelompok yaitu ketika menggunakan pendamping kasir dan tidak menggunakan pendamping kasir. Dengan bantuan komputer program Deskriptif Komparatif (Gempur Santoso, 2005)

\section{HASIL PENELITIAN}

Di dalam restoran wendys selalu padat pengunjung di waktu jam makan siang dan malam. didalam restoran antara pembeli masuk dan pelayanan pada kasir sangatlah tidak seimbang, pembeli yang mengantri semakin bertambah dan keterlambatan pelayanan si kasir membuat pelayanan menjadi terhambat.

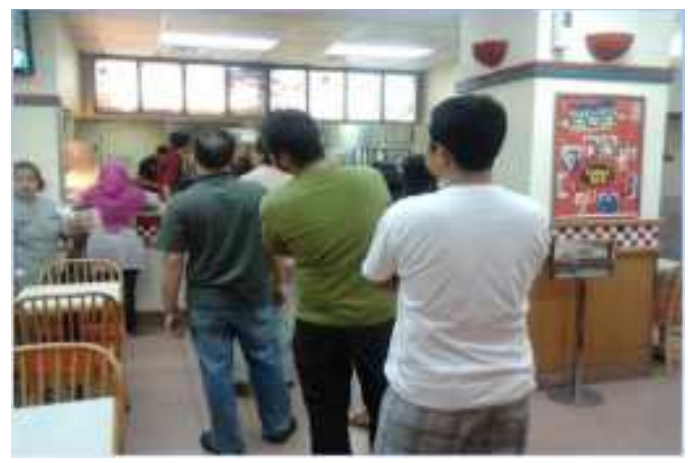

Gambar 1.1 Antrian

Dalam penelitian ini pengumpulan data dilakukan dengan menggunakan mencatat waktu antrian ketika orang tersebut membeli makanan sebagai sampel dari seluruh populasi orang yang mengantri di Restorant Wendys.

Tabel 1.1 Susunan antrian yang tidak menggunakan pendamping Kasir.

\begin{tabular}{clcc}
\hline No & \multicolumn{1}{c}{ Hari } & $\begin{array}{c}\text { Banyak } \\
\text { Antrian(Orang) }\end{array}$ & $\begin{array}{c}\text { Lama Memesan Per } \\
\text { Orang (Menit,Detik) }\end{array}$ \\
\hline 1 & Senin & 6 & 3 \\
2 & Selasa & 4 & 3 \\
3 & Rabu & 6 & 2 \\
4 & Kamis & 8 & 3 \\
5 & Jumat & 8 & 3 \\
6 & Sabtu & 10 & 3 \\
7 & Minggu & 10 & 3 \\
8 & Senin & 5 & 3 \\
9 & Selasa & 4 & 3 \\
10 & Rabu & 5 & 3 \\
& & Rata - rata & \\
\hline
\end{tabular}

Tabel 1.2 Susunan antrian yang menggunakan pendamping kasir

\begin{tabular}{|c|c|c|c|}
\hline No & Hari & $\begin{array}{c}\text { Banyaknya } \\
\text { Antrian }\end{array}$ & $\begin{array}{c}\text { Lama Memesan Per } \\
\text { Orang }\end{array}$ \\
\hline 1 & Senin & 6 & 1,11 \\
\hline 2 & Selasa & 3 & 0,55 \\
\hline 3 & Rabu & 4 & 1,3 \\
\hline 4 & Kamis & 6 & 1,45 \\
\hline 5 & Jumat & 8 & 1,07 \\
\hline 6 & Sabtu & 10 & 2 \\
\hline 7 & Minggu & 10 & 2,04 \\
\hline 8 & Senin & 3 & 0,15 \\
\hline 9 & Selasa & 5 & 1,48 \\
\hline 10 & Rabu & 5 & 1,3 \\
\hline \multicolumn{3}{|c|}{ Rata - } & 1,245 \\
\hline
\end{tabular}


Perbandingan Mean, Median, Mode, Range Waktu Antrian Antara Tidak Menggunakan Pendamping Kasir Dengan Menggunakan Pendamping Kasir

Tabel 1.3 Perbandingan Selisih Antara Tidak Menggunakan Pendamping Kasir Dengan Menggunakan Pendamping kasir.

\begin{tabular}{clccc}
\hline \multicolumn{5}{c}{ Waktu Antrian (menit,detik) } \\
\hline NO & Satuan & TPK & MPK & Selisih \\
1 & Mean & 6 & 1,245 & 4,755 \\
2 & Median & 5,5 & 1,3 & 4,2 \\
3 & Mode & 6 & 1,3 & 4,7 \\
4 & Range & 7 & 1,89 & 5,11 \\
\hline
\end{tabular}

Keterangan : TPK : Tidak menggunakan pendamping kasir,MPK : Menggunakan pendamping kasir

Dari hasil perhitungan data diatas dengan menggunakan metode deskriptif dapat di bandingkan selisihnya sebagai berikut : Untuk nilai mean, ini bisa di simpulkan bahwa menggunakan pendamping kasir orang yang lama mengantri lebih cepat 4,755 menit dibandingkan dengan yang tidak menggunakan pendamping kasir. Untuk nilai median, bisa disimpulkan bahwa yang menggunakan pendamping kasir lama mengantri mempunyai waktu lebih sedikit hanya 4,2 menit dibandingkan dengan yang tidak menggunakan pendamping kasir. Untuk nilai mode,di simpulkan bahwa yang lama mengantri ketika menggunakan pendamping kasir 4,7 menit lebih cepat dari pada yang tidak menggunakan pendamping kasir. Untuk nilai range yang lama mengantri menggunakan pendamping kasir hanya pendamping kasir.

\section{PEMBAHASAN}

Kasir Dari hasil data dan uji Deskriptif komparatif di atas bahwa peranan pendamping kasir sangatlah efektif untuk mengurangi antrian yang sangat panjang.maskipun tidak perlu menambah mesin kasir atau karyawan baru di Restoran Wendys tersebut. berdasarkan selisih waktu antara menggunakan pendamping kasir 1,245 menit dengan tidak menggunakan pendamping kasir 6 menit nilai rata-rata (mean) selisihnya 4,755 menit. berarti untuk lama mengantri dengan menggunakan pendamping kasir hanya menunggu 4,755 menit per antrian. Sedangkan tidak menggunakan pendamping kasir 6 menit atau lebih.

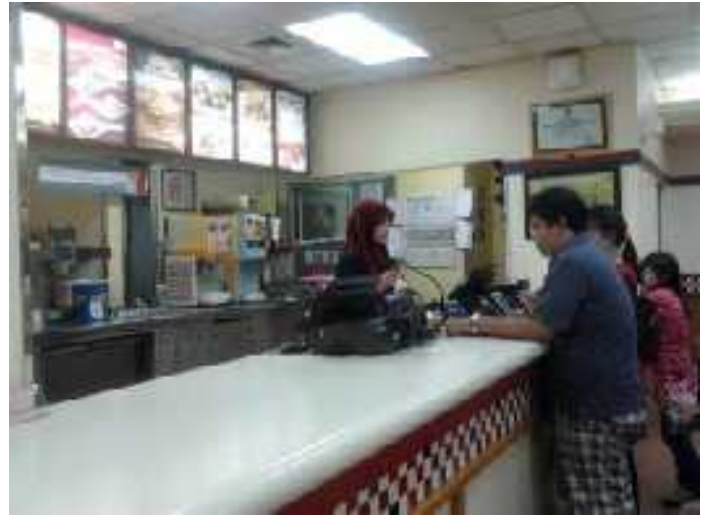

Gambar 1.2 tidak menggunakan pendamping kasir

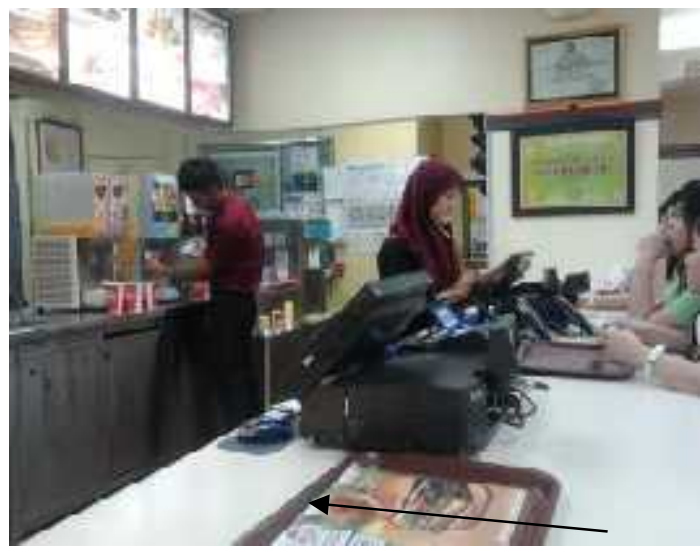

Gambar 1.3 menggunakan pendamping kasir.

\section{SIMPULAN DAN SARAN}

Dari hasil penelitian dan pembahasan analisis di atas bahwa lama antri antara menggunakan pendamping kasir lebih cepat 4,755 menit, di banding dengan tidak menggunakan pendamping kasir. 
Saran dari proses analisa data diatas bahwa sistem penambahan pendamping kasir sangatlah efektif untuk mengurangi antrian di restoran Wendys. Adapun saran yang di peroleh dari penelitian adalah sebagai berikut: Dari hasil analisis ini staff restoran Wendys dapat mempertimbangkan betapa pentingnya atau pengaruh dengan menggunakan pendamping kasir untuk menjadi solusi untuk mengurangi antrian yang panjang. Semakin cepat pelayanan pesanan, semakin besar peluang pembeli untuk mengunjungi restoran Wendys nya. Untuk bapak supervisor Wendys dengan adanya program analisa penambahan pendamping kasir ini, smoga bapak dapat menyimpulkan betapa pengaruhnya fasilitas menggunakan pendamping kasir untuk mengurangi antrian yang selama ini menjadi permasalahan di tempat bapak. Dan disamping itu juga sistem pendamping kasir yang sudah ada didalam restoran Wendys dapat di fungsikan lagi sebagaimana apabila jumlah karyawan sedikit atau kurang, bapak dapat menambah karyawan untuk mengisi sebagai pendamping kasir tersebut, tetapi apabila karyawan sudah merasa cukup, peneliti sarankan bapak dapat mengatur sistem penjadwalan (skeduling) karyawannya. Untuk semua karyawan Wendys dengan adanya sistem pendamping kasir ini smoga dapat bermanfaat untuk mengatasi masalah antrian yang panjang dan tidak teratur, agar pembeli yang antri juga merasa di perhatikan pelayananya.

\section{DAFTAR PUSTAKA}

A.Sobirin Suwandi,1973.Pendampingkasir.S.O.P WENDYS. SM manager. Bojonegoro.

Gempur Santoso, 2005. Metodologi Penelitian, Universitas Airlangga, Surabaya. Cetakan pertama

Siagian, P. 1987. Penelitian Operasional : Teori dan Praktek, Universitas Indonesia press.Jakarta.

Subagyo, pangestu, Suparyanto dkk. 2000. Dasar-dasar Operations research BPFE Yogyakarta. 